\title{
Designing Of Distributed Power-Flow Controller
}

\author{
${ }^{1}$ R. Lokeswar Reddy (M.Tech), ${ }^{2}$ K. Vasu M. Tech \\ I'Department of Electrical and Electronics Engineering, Madanapalle Institute of Science \& Technology, \\ Madanapalle-517325 \\ ${ }^{2}$ Asst. Professors, Department of Electrical and Electronics Engineering, Madanapalle Institute of Science \& \\ Technology, Madanapalle-517325,
}

\begin{abstract}
The growing demand and the aging of networks make it desirable to control the power flow in power-transmission systems fast and reliably. The Load changes the voltage Variation in transmission lines must be limited, other wise the consumer's equipments are damaged at distributed side. For reducing these types of problems to develop this controller. The DPFC (Distributed Power-Flow Controller) is derived from the unified power-flow controller (UPFC). The DPFC (Distribute Power-Flow Controller) modified from UPFC for increasing system reliability and reducing costs. The DPFC independently controlling the active and reactive power flow in transmission line. This paper consists of both active and reactive variations, using MATLAB/SIMULINK is simulated and its effects on the transmission lines observed. The simulated results are analyzed and validated with the real time results for the system considered.
\end{abstract}

Keywords: $A C-D C$ power conversion, filters, load flow control, power electronics, power-transmission control, power semiconductor devices, Power system control V-I measurements.

\section{Introduction}

The ability of FACTS controllers to control the interrelated parameters that govern the operation of transmission systems including series impedance, shunt impedance, current, voltage, phase angle, and the damping of oscillations at various frequencies below the rated frequency. These constraints cannot be overcome, whilemaintainingtherequiredsystemreliability, bymechanicalsystems means without lowering the useable transmission capacity. By providing added flexibility, FACTS Controllers can enable a line to carry power closer to its thermal rating. A transmission line can be characterized by four parameters: resistance, inductance, capacitance and conductance. Conductance accounts for the leakage current at the insulators of overhead lines. However, for a short and medium length line (less than $240 \mathrm{~km}$ ), the capacitance and conductance are so small that they can be neglected with little loss of accuracy. A transmission line can be characterized by four parameters: resistance, inductance, capacitance and conductance. Conductance Accounts for the leakage current at the insulators of overhead lines. However, for a short and medium length line (less than $240 \mathrm{~km}$ ), the capacitance and conductance are so small that they can be neglected with little loss of accuracy. The DPFC has the same Control capability as the UPFC, which comprises the adjustment of the line impedance, the transmission angle, and the bus voltage.

The UPFC is the combination of a static synchronous compensator (STATCOM) and a static synchronous series compensator (SSSC), which are coupled via a common dc link, to allow bidirectional flow of active power between the series output terminals of the SSSC and the shunt output terminals of the STATCOM.

\subsection{Static Synchronous Series Compensator (SSSC)}

A static, synchronous generator operated without an external electric energy source as a series compensator whose output voltage is in quadrature with and Controllable independently of, the line current for the purpose of increasing or decreasing the overall reactive voltage drop across the line and thereby controlling the transmitted electric power. The SSSC may include transiently rated energy storage or Energy absorbing devices to enhance the dynamic behaviour of the power system by additional temporary real power compensation, to increase or decrease momentarily, the overall real (resistive) voltage drop across the line. An impedance compensation controller can compensate for the transmission line resistance if an SSSC is operated with an energy storage system. An impedance compensation controller, when used with an SSSC and no energy storage system, is essentially a reactance compensation controller. The reactance compensation controller is used to operate the inverter in such a way that the injected alternating voltage in series with the transmission line is proportional to the line current with the emulated reactance being the constant of proportionality. When an SSSC injects an alternating voltage leading the line current, it emulates an inductive reactance in series with the transmission line causing the power flow as well as the line current to decrease as the level of compensation increases and the SSSC is considered to be operating in an inductive mode. When an SSSC injects an alternating voltage lagging the line current, it emulates a capacitive reactance in series with the transmission line causing 
the power flow as well as the line current to increase as the level of compensation increases and the SSSC is considered to be operating in a capacitive mode. An impedance compensation controller can compensate for the transmission line resistance if an SSSC is operated with an energy storage system. An impedance compensation controller, when used with an SSSC and no energy storage system, is essentially a reactance compensation controller. The reactance compensation controller is used to operate the inverter in such a way that the injected alternating voltage in series with the transmission line is proportional to the line current with the emulated reactance being the constant of proportionality. When an SSSC injects an alternating voltage leading the line current, it emulates an inductive reactance in series with the transmission line causing the power flow as well as the line current to decrease as the level of compensation increases and the SSSC is considered to be operating in an inductive mode. When an SSSC injects an alternating voltage lagging the line current, it emulates a capacitive reactance in series with the transmission line causing the power flow as well as the line current to increase as the level of compensation increases and the SSSC is considered to be operating in a capacitive mode.

\subsection{Static Synchronous Compensator (STATCOM)}

A static synchronous generator operated as a shunt-connected static var compensator whose capacitive or inductive output current can be controlled independent of the ac system voltage.

\subsection{Series Converter}

The series converter executes the main function of the UPFC by injecting a voltage, with controllable magnitude and phase angle, in series with the transmission line. It is controlled to provide concurrent active and reactive series compensation without an external energy source. By means of the series voltage injection without angular constraint, the UPFC is able to control, concurrently or selectively, the transmission angle, impedance and line voltage or, alternatively, active and reactive power flow through the line. The voltage injected by the series converter results in active and reactive power exchange between the series converter and the transmission line. The reactive power is generated internally by the series converter (SSSC), and the active power is supplied by the shunt converter that is transported through the common DC link.

\subsection{Shunt Converter}

The basic function of the shunt converter is to supply or absorb the active power demanded by the series converter. The shunt converter controls the voltage of the DC capacitor by absorbing or generating active power from the bus, therefore it acts as a synchronous source in parallel with the system. Similar to the STATCOM, the shunt converter can also provide independently controllable reactive compensation for the bus.

Considering its control capability, the UPFC can have the functions:

- Voltage regulation by continuously varying in-phase/anti-phase voltage injection that is similar to a tapchange transformer.

- Series reactive compensation by injecting a voltage that is in quadrature to the line current. Functionally, this is similar to an SSSC that can provide a controllable inductive and capacitive series compensation.

- Phase shifting by injecting a voltage with an angular relationship with respect to the bus voltage. By varying the magnitude of this voltage, the phase shift can be controlled.

The components of the UPFC handle the voltages and currents with high rating; therefore, the total cost of the system is high. Due to the common dc-link interconnection, a failure that happens at one converter will influence the whole system. To achieve the required reliability for power systems, bypass circuits and redundant backups (backup transformer, etc.) are needed, which on other hand, increase the cost. Accordingly, the UPFC has not been commercially used, even though; it has the most advanced control capabilities. This paper introduces a new concept, called distributed power-flow controller (DPFC) that is derived from the UPFC.The same as the UPFC, the DPFC is able to control all system parameters. The DPFC eliminates the common dc link between the shunt and series converters. The active power exchange between the shunt and the series converter is through the transmission line at the third-harmonic frequency. The series converter of the DPFC employs the distributed FACTS (D-FACTS) concept [6]. Comparing with the UPFC, the DPFC have two major advantages:

1) Low cost because of the low-voltage isolation and the low component rating of the series Converter and

2) High reliability because of the redundancy of the series converters. 


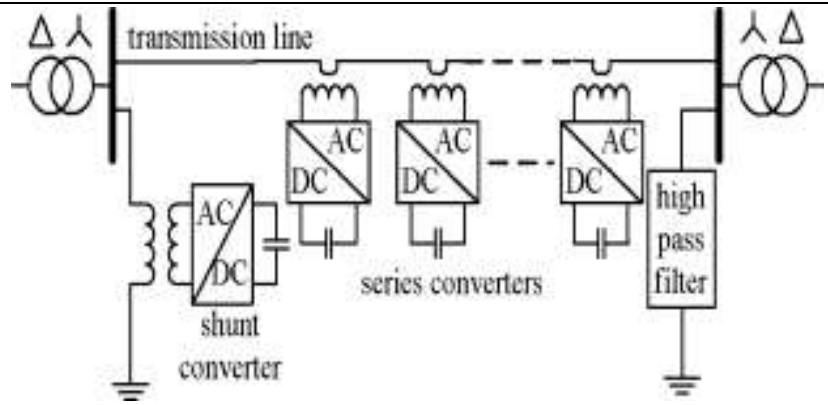

Fig.1. DPFC Configuration.

Advantages of the DPFC over UPFC:

The DPFC can be considered as a UPFC that employs the DFACTS concept and the concept of exchanging power through harmonic. Therefore, the DPFC inherits all the advantages of the UPFC and the DFACTS, which are as follows.

1) High control capability

The DPFC can simultaneously control all the parameters of the power system: the line impedance, the transmission angle, and the bus voltage. The elimination of the common dc link enables separated installation of the DPFC converters. The shunt and series converters can be placed at the most effectively location. Due to the high control capability, the DPFC can also be used to improve the power quality and system stability, such as low-frequency power oscillation damping [8], voltage sag restoration, or balancing asymmetry.

\section{2) High reliability}

The redundancy of the series converter gives an improved reliability. In addition, the shunt and series converters are independent, and the failure at one place will not influence the other converters. When a failure occurs in the series converter, the converter will be short-circuited by bypass protection, thereby having little influence to the network. In the case of the shunt converter failure, the shunt converter will trip and the series converter will stop providing active compensation and will act as the D-FACTS controller [9].

\section{3) Low cost}

There is no phase-to-phase voltage isolation Required by the series converter. Also, the power rating of each converter is small and can be easily produced in Series production lines.

\subsection{Active power exchange with eliminated DC link}

\section{DPFC Operating Principle}

Within the DPFC, the transmission line presents a common connection between the AC ports of the shunt and the series converters. Therefore, it is possible to exchange active power through the AC ports. The method is based on power theory of non-sinusoidal components. According to the Fourier analysis, nonsinusoidal voltage and current can be expressed as the sum of sinusoidal functions in different frequencies with different amplitudes. The active power resulting from this non-sinusoidal voltage and current is defined as the mean value of the product of voltage and current. Since the integrals of all the cross product of terms with different frequencies are zero, the active power can be expressed by:

$$
\mathrm{P}=v_{I} i_{I} \cos \emptyset_{I}
$$

By applying this method to the DPFC, the shunt converter can absorb active power from the grid at the fundamental frequency and inject the power back at a harmonic frequency. This harmonic active power flows through a transmission line equipped with series converters. According to the amount of required active power at the fundamental frequency, the DPFC series converters generate a voltage at the harmonic frequency, thereby absorbing the active power from harmonic components. Neglecting losses, the active power generated at the fundamental frequency is equal to the power absorbed at the harmonic frequency.

\subsection{Using third harmonic components}

Due to the unique features of 3rd harmonic frequency components in a three-phase system, the 3rd harmonic is selected for active power exchange in the DPFC. In a three-phase system, the 3rd harmonic in each phase is identical, which means they are 'zero-sequence' Components. Because the zero-sequence harmonic can be naturally blocked by star-delta transformers and these are widely incorporated in power systems (as a means of changing voltage), there is no extra filter required to prevent harmonic leakage. 


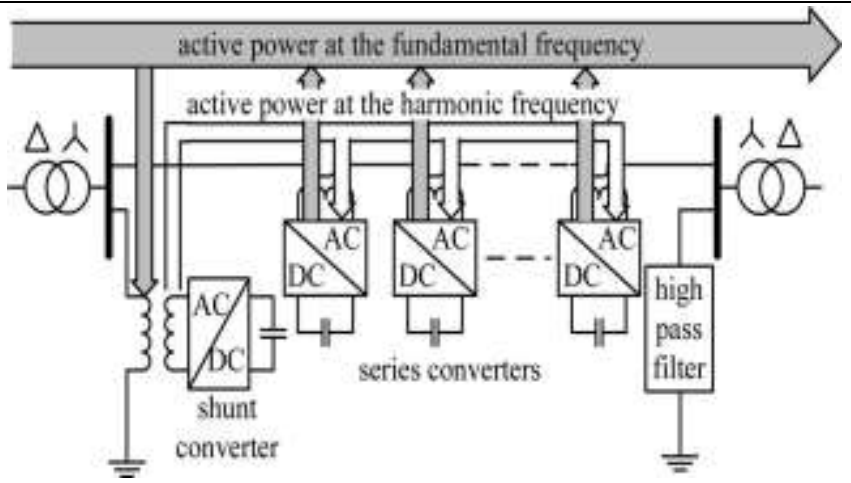

Fig. 2. Active power exchange between DPFC converters

\section{DPFC Control}

To control multiple converters, a DPFC consists of three types of controllers: central control, shunt control and series control, The shunt and series control are localized controllers and are responsible for maintaining their own converters' parameters. The central control takes care of the DPFC functions at the power system level. The function of each controller is listed:

\section{- Central control}

The central control generates the reference signals for both the shunt and series converters of the DPFC. Its control function depends on the specifics of the DPFC application at the power system level, such as power flow control, low frequency power oscillation damping and balancing of asymmetrical components. According to the system requirements, the central control gives corresponding voltage reference signals for the series converters and reactive current signal for the shunt converter. All the reference signals generated by the central control concern the fundamental frequency components.

\section{- Series control}

Each series converter has its own series control. The controller is used to maintain the capacitor DC voltage of its own converter, by using $3^{\text {rd }}$ harmonic frequency components, in addition to generating series voltage at the fundamental frequency as required by the central control.

- Shunt control

The objective of the shunt control is to inject a constant $3^{\text {rd }}$ harmonic current into the line to supply active power for the series converters. At the same time, it maintains the capacitor DC voltage of the shunt converter at a constant value by absorbing active power from the grid at the fundamental frequency and injecting the required reactive current at the fundamental frequency into the grid.

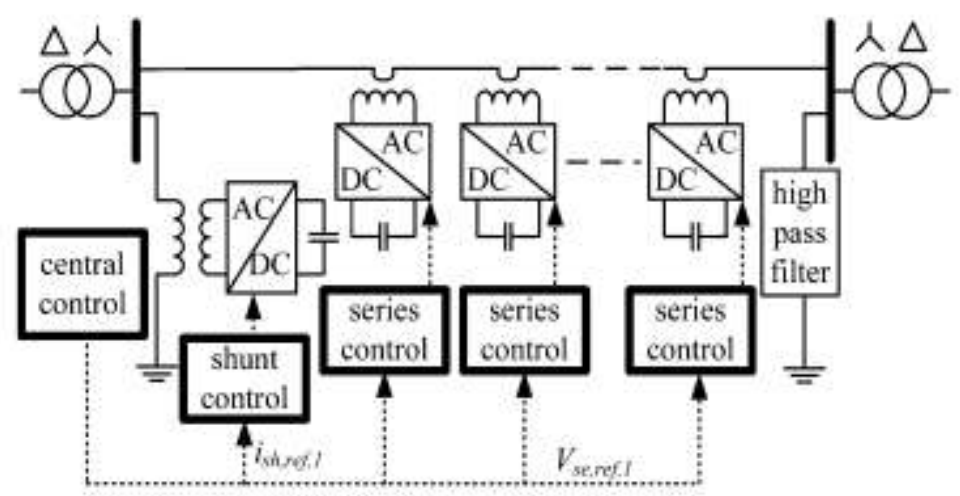

Fig. 3. DPFC configuration.

The third-harmonic frequency control is the major control loop with the DPFC series converter control. The principle of the vector control is used here for the dc-voltage control [10]. The third-harmonic current through the line is selected as the rotation reference frame for the single-phase park transformation, because it is easy to be captured by the phase-locked loop (PLL) [11] in the series converter. As the line current contains two frequency components, a third high-pass filter is needed to reduce the fundamental current. The $d$-component of the third harmonic voltage is the parameter that is used to control the dc voltage, and its reference signal is 
generated by the dc-voltage control loop. To minimize the reactive power that is caused by the third harmonic, the series converter is controlled as a resistance at the third-harmonic frequency. The $q$-component of the thirdharmonic voltage is kept zero during the operation. As the series converter is single phase, there will be voltage ripple at the dc side of each converter. The frequency of the ripple depends on the frequency of the current that flows through the converter. As the current contains the fundamental and third harmonic frequency component, the dc-capacitor voltage will contain 100-, 200-, and 300-Hz frequency component [12], [13].

There are two possible ways to reduce this ripple. One is to increase the turn ratio of the single-phase transformer of thel series converter to reduce the magnitude of the current that flows into the converter. The other way is to use the dc capacitor with a larger capacitance.

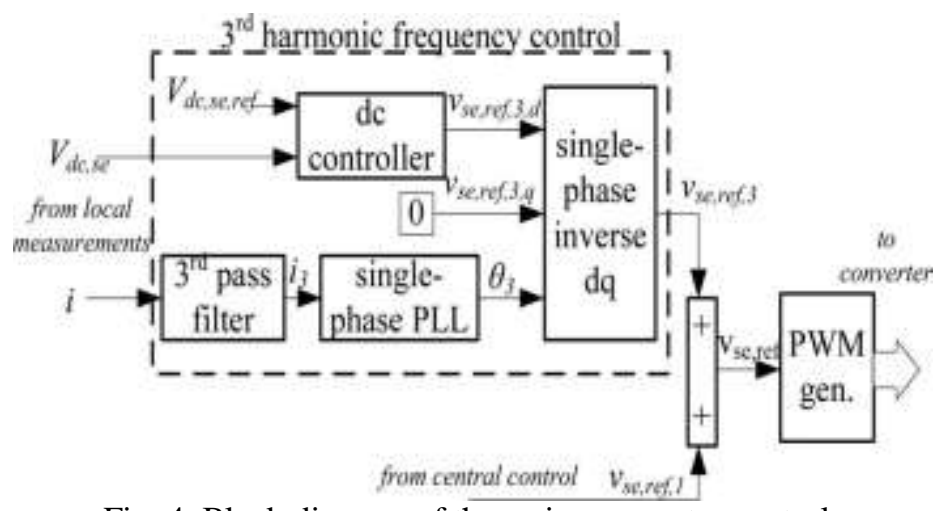

Fig. 4. Block diagram of the series converter control.

The objective of the shunt control is to inject a constant third harmonic current into the line to provide active power for the series converters. The third-harmonic current is locked with the bus voltage at the fundamental frequency. A PLL is used to capture the bus-voltage frequency, and the output phase signal of the PLL is multiplied by three to create a virtual rotation reference frame for the third-harmonic component. The shunt converter's fundamental frequency control aims to inject a controllable reactive current to grid and to keep the capacitor dc voltage at a constant level.

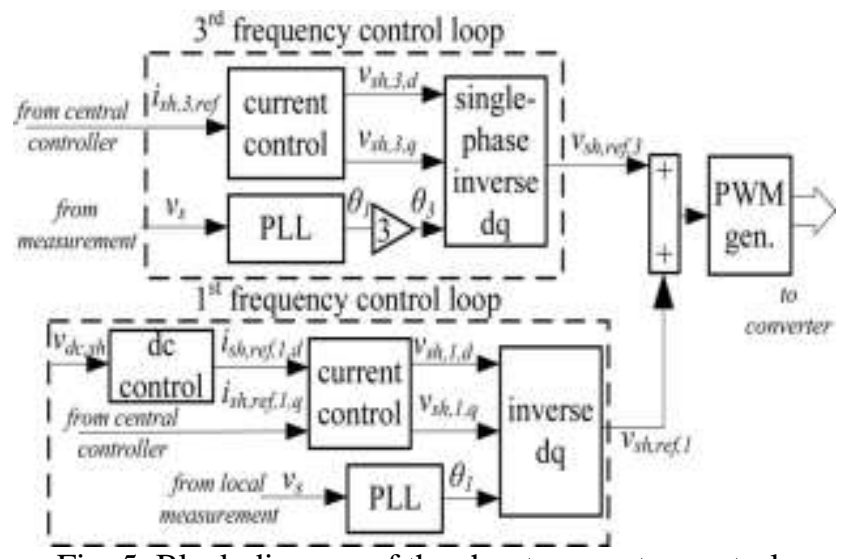

$\overline{\text { Fig. }} \overline{5}$. Block diagram of the shunt converter control.

The control for the fundamental frequency components consists of two cascaded controllers. The current control is the inner control loop, which is to modulate the shunt current at the fundamental frequency. The $q$-component of the reference signal of the shunt converter is obtained from the central Controller and $d$ component is generated by the dc control. 
TABLE SPECIFICATIONS OF THE DPFC

\begin{tabular}{|c|c|c|c|}
\hline Symbol & Description & Value & Unit \\
\hline $\mathrm{Vs}$ & $\begin{array}{c}\text { Nominal voltage of grid } \\
\text { s }\end{array}$ & 220 & $\mathrm{~V}$ \\
\hline $\mathrm{Vr}$ & $\begin{array}{c}\text { Nominal voltage of grid } \\
\mathrm{r}\end{array}$ & 220 & $\mathrm{~V}$ \\
\hline $\mathrm{L}$ & $\begin{array}{c}\text { transmission angle } \\
\text { between between grid s } \\
\text { and r }\end{array}$ & 1 & $\mathrm{o}$ \\
\hline $\begin{array}{c}\text { Vsh,ma } \\
\mathrm{x}\end{array}$ & $\begin{array}{c}\text { Shunt Converter } \\
\text { maximum ac voltage } \\
\text { Shunt Converter } \\
\text { maximum ac voltage }\end{array}$ & 50 & $\mathrm{~V}$ \\
\hline $\begin{array}{c}\text { Ish,max } \\
\text { Vsh,dc }\end{array}$ & $\begin{array}{c}\text { Shunt Converter dc } \\
\text { source supply }\end{array}$ & 20 & $\mathrm{~V}$ \\
\hline $\begin{array}{c}\text { Ish,ref,3 } \\
\text { Reference third-ie } \\
\text { current injected by the } \\
\text { shunt converter }\end{array}$ & 3 & $\mathrm{~A}$ \\
\hline Fs $\omega$ & $\begin{array}{c}\text { Switching frequency for } \\
\text { the shunt and series } \\
\text { converter }\end{array}$ & 6 & $\mathrm{kHz}$ \\
\hline $\begin{array}{c}\text { Vse,ma } \\
\mathrm{x}\end{array}$ & $\begin{array}{c}\text { maximum ac voltage at } \\
\text { line side of series } \\
\text { converter }\end{array}$ & 7 & $\mathrm{~V}$ \\
\hline Ise,max & $\begin{array}{c}\text { maximum ac current at } \\
\text { line side of series } \\
\text { converter }\end{array}$ & 15 & $\mathrm{~A}$ \\
\hline
\end{tabular}

One shunt converter and three single-phase series converters are built and tested in a scaled network, as shown in fig.6
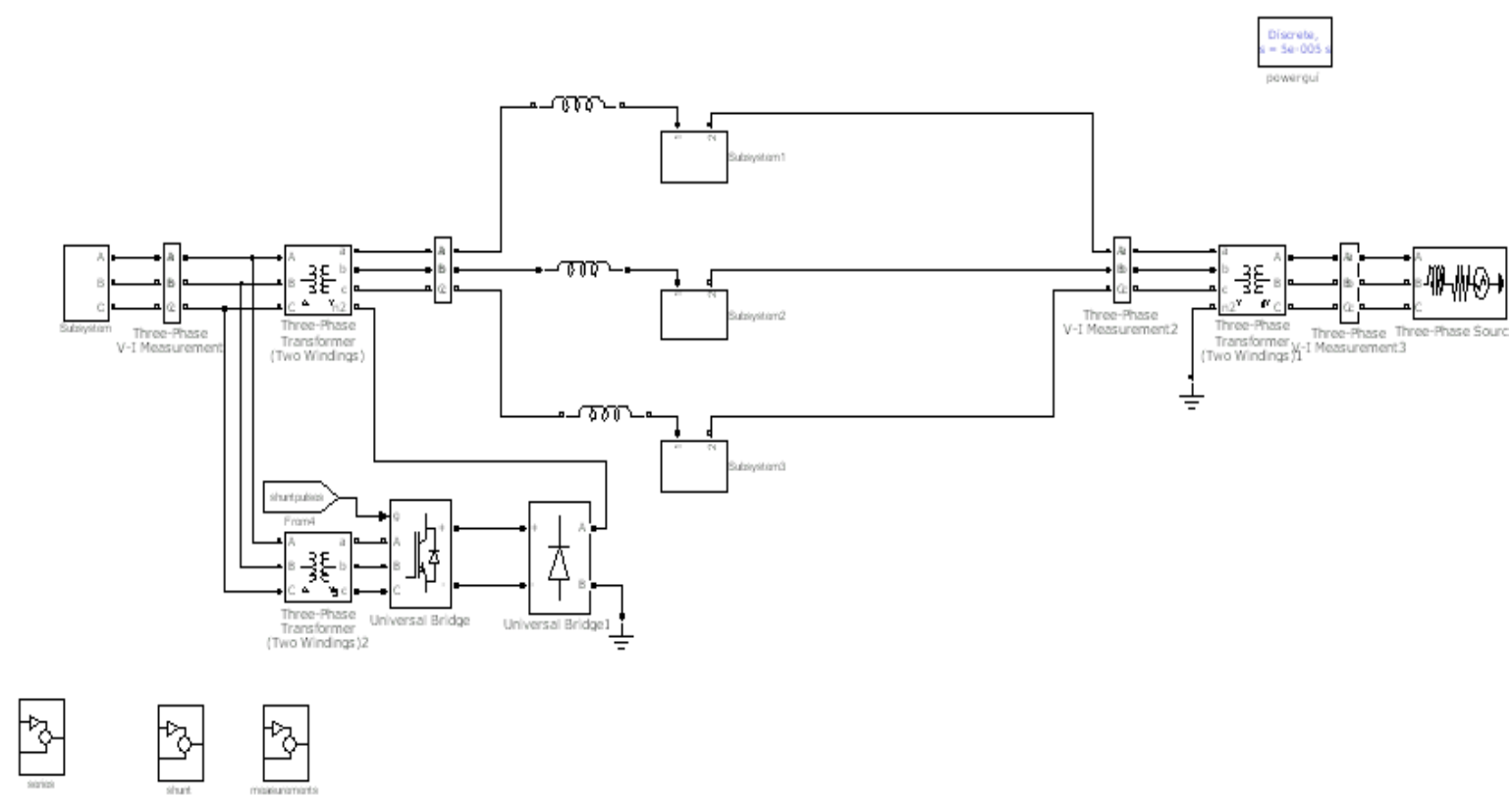

Fig.6 Simulated Model for DPFC 


\section{Series Converter SIMULINK Model}

Within the setup, multiple series converters are controlled by a central controller. The central controller gives the reference voltage signals for all series converters. The voltages and current within the setup are measured by its simulink outputs.

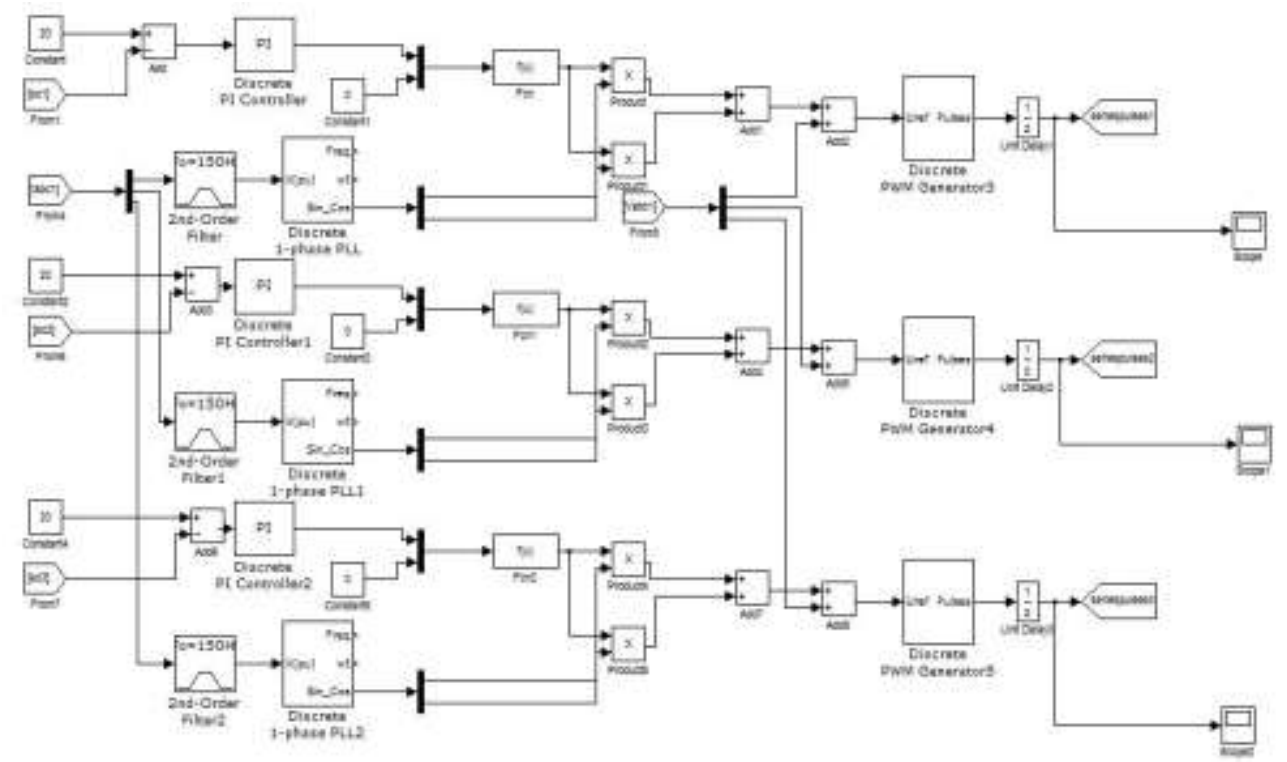

Fig.7 Simulated model for series converter

\subsection{Shunt Converter SIMULINK Model}

The basic function of the shunt converter is to supply or absorb the active power demanded by the series converter. The shunt converter controls the voltage of the DC capacitor by absorbing or generating active power from the bus, therefore it acts as a synchronous source in parallel with the system. To verify the DPFC principle, two situations are demonstrated: the DPFC behavior in steady state and the step response. In steady state, the series converter is controlled to insert a voltage vector with both $d$ - and $q$-component, which is $V$ se, d,ref $=0.3 \mathrm{~V}$ and $V$ se, q,ref $=-0.1 \mathrm{~V}$. Figs. 19-21 show one operation point of the DPFC setup. The voltage injected by the series converter, the current through the line, and the voltage and current at the $\Delta$ side of the transformer.

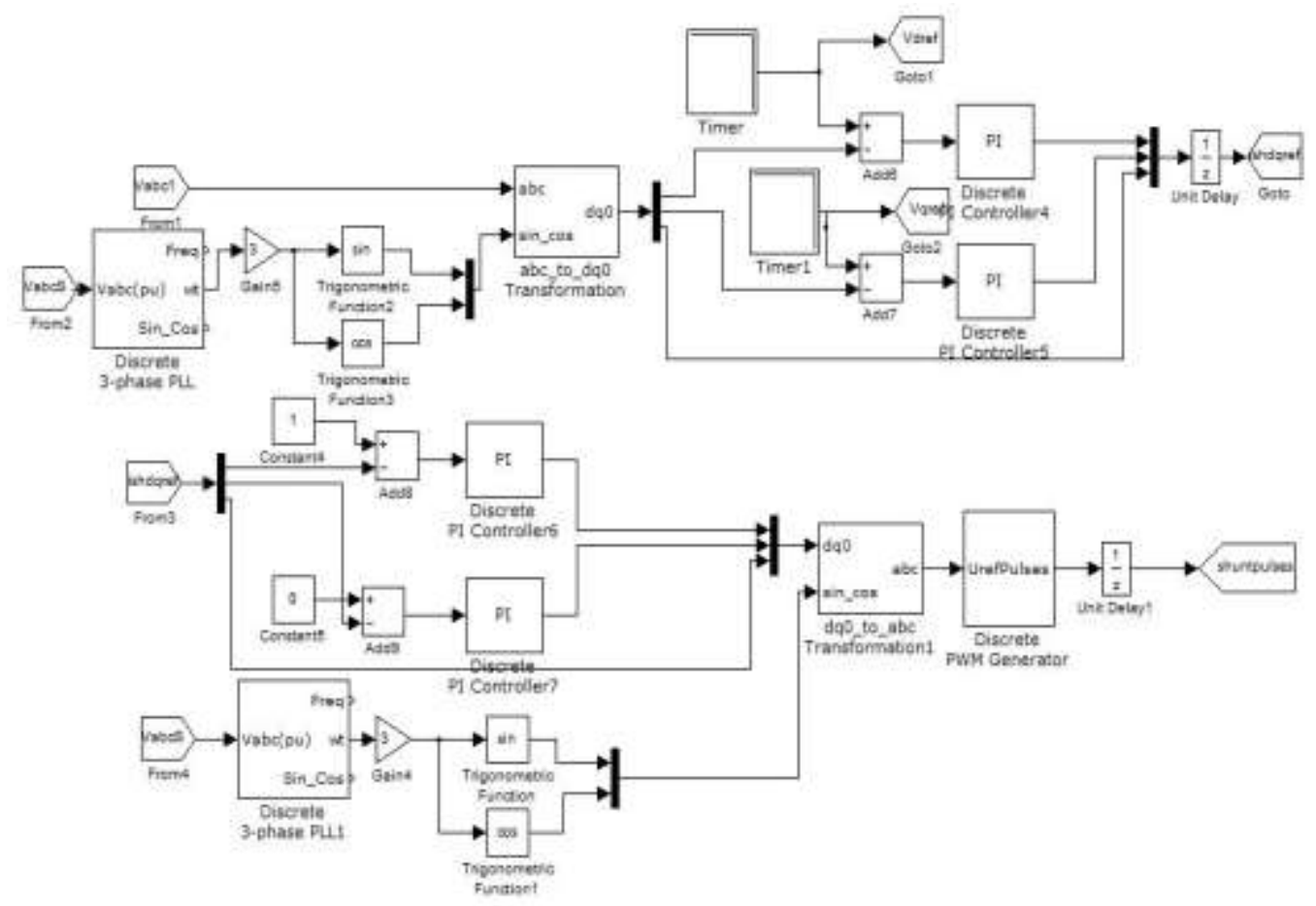

Fig.8 Simulated model for shunt converter 
V. Results

5.1Reference voltage for the series converters:

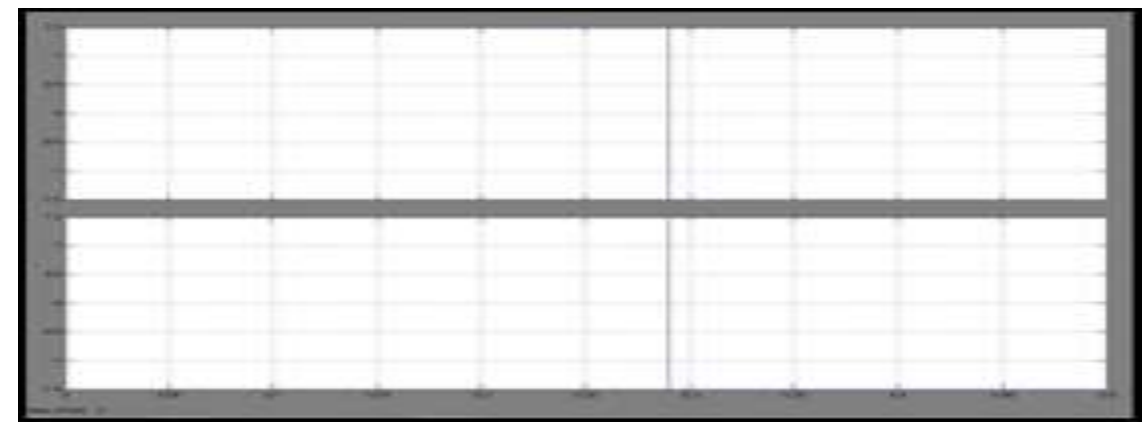

5.2 Step response of the DPFC: line current:

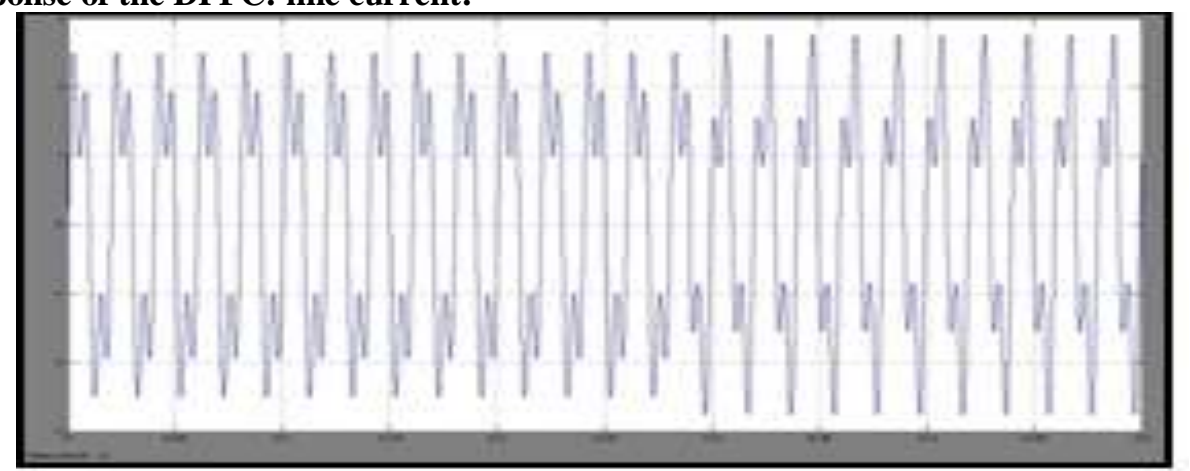

5.3Step response of the DPFC: active and reactive power injected by the Series converter:

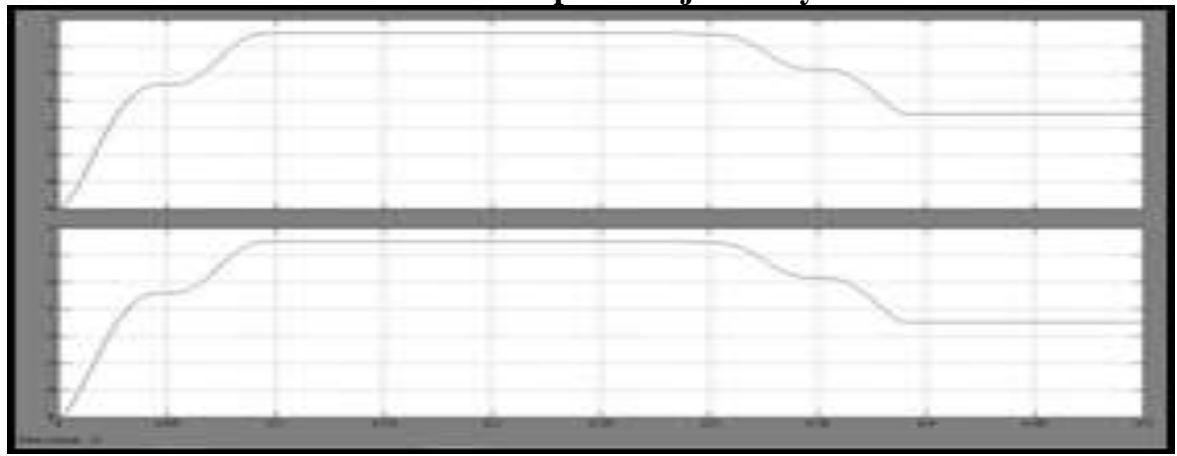

5.4 Step response of the DPFC: bus voltage and current at the $\square$ side of the transformer:

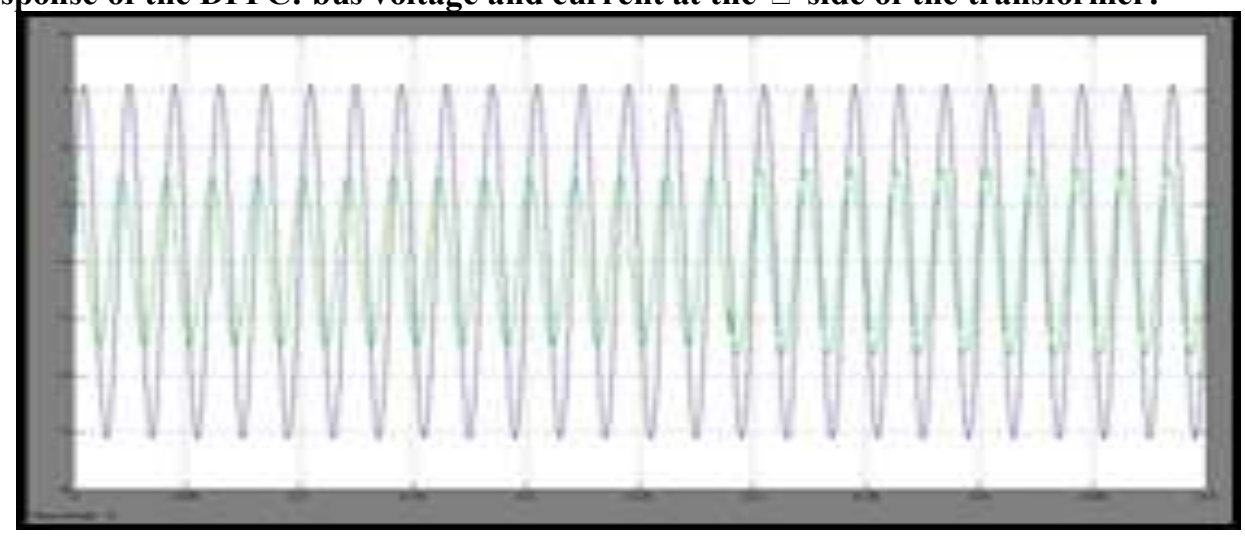


5.5 Step response of the DPFC: series converter voltage.

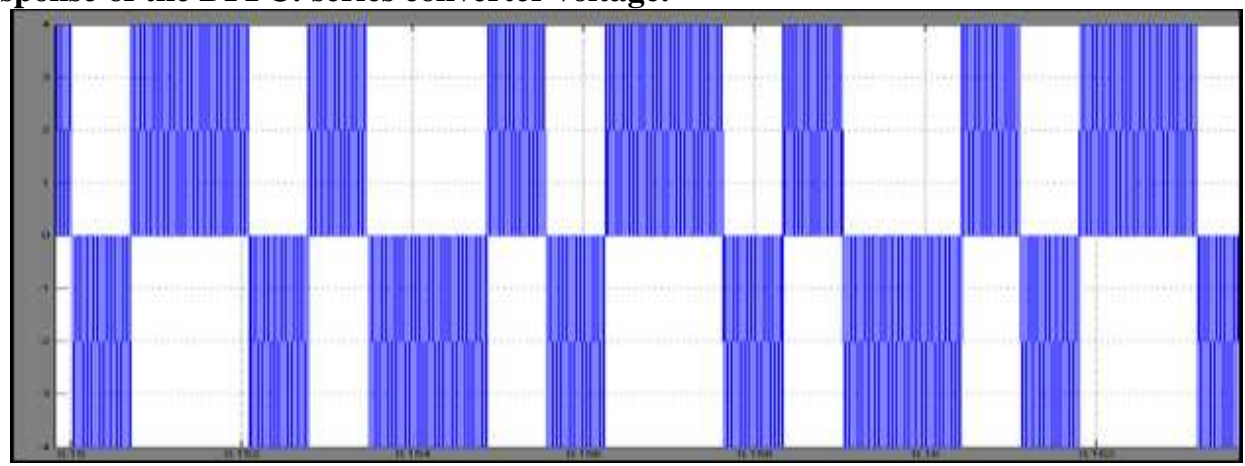

\section{Conclusions}

The DPFC emerges from the UPFC the common dc link between the shunt and series converters, which is use for exchanging active power in the UPFC, is eliminated. The DPFC reducing the total cost and increasing the reliability comparing with UPFC.The DPFC emerges from the UPFC and inherits the control capability of the UPFC, which is the simultaneous adjustment of the line impedance, the transmission angle, and the bus-voltage magnitude. The common dc link between the shunt and series converters, which is used for exchanging active power in the UPFC, is eliminated. This power is now transmitted through the transmission line at the third-harmonic frequency. The series converter of the DPFC employs the D-FACTS concept, which uses multiple small single-phase converters instead of one large-size converter. The reliability of the DPFC is greatly increased because of the redundancy of the series converters. The total cost of the DPFC is also much lower than the UPFC, because no high-voltage isolation is required at the series-converter part and the rating of the components of is low.It is proved that the shunt and series converters in the DPFC can exchange active power at the third-harmonic frequency, and the series converters are able to inject controllable active and reactive power at the fundamental frequency.

\section{References}

[1] N. G. Hingorani and L. Gyugyi, Understanding FACTS: Concepts and Technology of Flexible AC Transmission Systems. New York: IEEE Press, 2000.

[2] K.K.Sen.,"Sssc-static synchronous series compensator: Theory, modeling, and application,” IEEE Trans. Power Del., vol. 13, no. 1, pp. 241-246, Jan. 1998.

[3] N. Mohan, T. M. Undeland, and W. P. Robbins, Power Electronics : Converters, Applications, and Design, 3rd ed. Hoboken, NJ: Wiley, 2003.

[4] M. Mohaddes, A. M. Gole, and S. Elez, "Steady state frequency response of statcom," IEEE Trans. Power Del., vol. 16, no. 1, pp. 18-23, Jan. 2001.

[5] Static Synchronous Series Compensator: A Solid-state Approach to the Series Compensation of Transmission Lines, L. Gyugyi, C. D. Schauder and K. K. Sen, 96 WM 120-6 PWRD, IEEE PES Winter Meeting, 1996.

[6] L. Gyugyi, C. D. Schauder, S. L. Williams, T. R. Rietman, D. R. Torgerson, and A. Edris, "Unified power flow controller: A new approach to power transmission control," IEEE Trans. Power Delivery, vol. 10, no.2, pp. 1085-1093, Apr. 1995.

[7] Y.-H. Song and Y.-H. Song and A. Johns, Flexible ac Transmission Systems (FACTS) (IEE Power and Energy Series), vol. 30. London, U.K.: Institution of Electrical Engineers, 1999. A. Johns, Flexible ac Transmission Systems (FACTS) (IEEE Power and Energy Series), vol. 30. London, U.K.: Institution of Electrical Engineers, 1999. 